\title{
THE COVID-19 PANDEMIC AND FACE SHIELDS: A REVIEW
}

\author{
Jennifer $\mathrm{Ha}^{1}$
}

${ }^{1}$ Affiliation not available

July 6, 2020

\begin{abstract}
Introduction The coronavirus disease 2019 (COVID-19) pandemic has placed personal protective equipment (PPE) for healthcare workers $(\mathrm{HCW})$ in the spotlight. HCW's face has been reported to be the body part most commonly contaminated by body fluids. The aim of this narrative review to examine the current evidence on face shield as a PPE for droplet or aerosol prevention. Methods A literature search was conducted on the PubMed, MedLine, and Embase databases, with the keywords "face shield", "visor", and "droplet precaution". Bibliographic search was also undertaken. Results Respiratory droplet is particle with diameter greater than $5 \mu \mathrm{m}$, while aerosol are [?]5 $\mathrm{m}$ according to the World Health Organisation. However, infection is not neatly separated into the dichotomy of droplet versus airborne transmission route. Modelling and simulation have shown the importance of the conjunctival mucosa as a route of transmission of disease in blood splashes, droplets and aerosols containing virus. The limited reports from SARS, COVID-19 and influenza season supports its use. However, HCW do not routinely use face shield if they consider the procedures to be unlikely to be associated with potential contamination. They also erroneously believe that prescription glasses is adequate protection. The issues associated with eye shield use, may be less of a problem with face shield. Conclusion Transmission of viruses is multimodal, and the conjunctival mucosa presents a real risk for viral transmission. Eye and face protection is important to prevent transmission of COVID-19.
\end{abstract}

\section{TAKE HOME MESSAGES}

- Conjunctival mucosa presents a real risk for transmission in blood splashes, droplets or aerosols with viable virus, including SARS-CoV-2.

- HCW often do not detect contaminations to the eye resulting in low compliance of eye protection due to perceived low risk and erroneous belief that prescription glasses is adequate protection.

- Modelling and simulation have shown importance of the face shield use in droplet precaution.

\section{KEYWORDS}

COVID-19, face shield, personal protective equipment, health care worker, eye protection, visor, mask visor

\section{INTRODUCTION}

The coronavirus disease 2019 (COVID-19) pandemic has placed personal protective equipment (PPE) for healthcare workers (HCW) in the spotlight. Certain professions, like dentists and otorhinolaryngologists have a higher overall cumulative risk of exposure to splash, droplets and aerosols during their clinical practice.

The global shortage of PPE for HCW, has resulted in vulnerability to the transmission of CVOID-19 and mortality. HCW's face has been reported to be the body part most commonly contaminated by body fluids.(1) There are other occupational hazards apart from COVID-19. The cumulative lifetime risk of a surgeon becoming infected with hepatitis $\mathrm{C}$ is $6.9 \%$ and HIV is $0.15 \%$.(2) The estimated HIV transmission risk with mucocutaneous contact is $0.1 \%$.(2) 
Transmission is influenced by various factors like: Pathogens, ventilation, air filtration, sterilization and PPE.(3) A face shield is a PPE that provides barrier protection to the facial area and related mucus membranes of the eyes, nose and lips, from spray or splash blood, body fluids, secretions or excretions. $(1,4)$ It has received less attention compared to surgical masks and respirators. This is likely because it is easily manufactured, and industry like 3 dimensional printing, or additive manufacturing has stepped in.

The aim of this narrative review to examine the current evidence on face shield as a PPE for droplet or aerosol prevention.

\section{METHOD}

A literature search was conducted on the PubMed, MedLine, and Embase databases, with the keywords "face shield", "visor", and "droplet precaution". Bibliographic search was also undertaken. The abstracts were scanned to assess their appropriateness to be included in this narrative review.

\section{DISCUSSION}

PPE recommended for droplet precautions include gloves, gown, surgical mask and eye protection and or face shield, depending on the anticipated exposure to patient secretions.

Face shield captures body fluid splatters, and alters the particle size distribution and magnitude of inhaled aerosols.(5) It covers a larger area than a face mask with visor or goggles, and limit splash and sprays on to face, surgical masks and respirators, which may increase the risk of self contamination during doffing.(5) Occupational Safety and Health Administration (OSHA) mandates that masks in combination with eye protection devices such as glasses with solid side shields, goggles, or chin length face shields when splashes, spray, splatter or droplets of blood or other potentially infectious material may be generated, and eye, nose or mouth contamination can be reasonably anticipated.(6)

There are several parts to it: Visor, frame, and suspension system.(1) Shields are manufactured from polycarbonate, proprionate, acetate, polyvinyl chloride and polyethylene terephthalate glycol (PETG).(7) It can be disposable, reusable, and replaceable.(1) Acetate provides the best clarity and is scratch resistant.(1) PETG is the most economical.(7) Polycarbonate is most widely used as it offers better optical quality that reduces eye strain associated with face shield wear.(1) Proprionate also has the similar optical quality as polycarbonate, and is the cheaper option. $(1,7)$ The shields can be treated with coatings to impart anti-glare, anti-static, and anti-fogging properties.(1) The length varies from mid-face to the neck, and the width should reach at least to the point of the ear (recommendation from Centers for Disease Control and Prevention) to reduce the likelihood a splash going around the edge to reach the eyes. Crown and chin protection is recommended for improved infection control purposes.(1) This will reduce the risk of possible ocular inoculation.

There is less retained dermal facial heat, less fogging compared to goggles, can be worn concurrently with other eye PPE, less claustrophobic and can be disinfected easily. It is inexpensive. However some may not fit over certain respirators. Industrial face shields, in the event of face shield shortages tend to be more expensive, heavier and bulkier.

\section{Droplet vs Aerosol}

The new $\beta$-coronavirus belonging to the subgenus botulinum of Coronaviridae is a chimeric virus between a bat coronavirus and a coronavirus of unknown origin. $(8,9)$

Respiratory droplets $(5-50 \mu \mathrm{m})$ is the main route of transmission, which is affected by gravity, and may cause direct transmission via close contact (including the conjunctivae), or via surface contamination.(10-19) SARS-nCoV-2 can remain infectious on inanimate surfaces at room temperature for up to 9 days.(20)

It is highly contagious and can be transmitted via smaller aerosols with a droplet nuclei [?]5um, which can travel long distances and remain airborne for $2-4$ hours, depending on the ambient conditions (temperature, humidity and ventilation).(21-23) The size and number of droplets produced is dependent on exhalation velocity (higher velocity results in finer and greater droplets).(21) The particle size determines the location 
in the respiratory tract it is deposited when it is inhaled. $(21,23)$ Large droplets $(>5 \mu \mathrm{m})$ rapidly fall to the ground when produced by coughing or sneezing.(21) Certain events (eg coughing or sneezing, cardiopulmonary resuscitation) and aerosol generating procedures (AGP) (eg intubation, tracheostomy) can generate aerosols composed of smaller virus containing particles suspended in air.(18)

Modelling of droplet sizes of less than $60 \mu \mathrm{m}$ can travel more than 2 meters, with reports up to 8 meters.(24) Droplets produced during coughing and sneezing travel a meter from the mouth, and some may travel as far as 3 meters away but the amount of virus is lower the further away.(25) During a cough, droplets of airway secretions become airborne and is expelled from the mouth in a high velocity aerosol plume.(25) The aerosol droplets generated during coughing span a broad size range, and dispersion in the environment depends on the size: Smaller aerosol may remain airborne and spread throughout the room, while larger droplets may settle onto surfaces, impact on the face/eyes.(25) The droplet size is dynamic and changes during its transit from the respiratory tract to the environment with evaporation, and a large droplet can become an airborne particle in less than a second.(24) This is dependent on the type of aerosol generating procedure, temperature, relative humidity, ventilation and air exchanges in the environment.(24) Aerosolised viable SARS-CoV-2 virus has been be detected in the air up to 3 hours after.(26)

However, infection is not neatly separated into the dichotomy of droplet versus airborne transmission route. $(27,28)$ There is heterogeneity of the viral load between patients and the quantity of aerosol particles generated. $(23,25)$

\section{The Risk}

\subsection{Splashes}

There is an overall 22.3-76.9\% risk of contamination from blood and body fluid splash on protective eye shields during surgery. $(2,29-35)$ The risk depends on the type of surgery, proximity to the operative field, type of diathermy used, and is proportional to the length of procedure and intra-operative blood loss. Depending on the type of surgery, mask with visors may not protect adequate protection.(36) Sing VK et al reported contamination of both the surgeon's and assistant's face during orthopaedic surgery.(36)

Chong et al's mathematical models have shown that prescription glasses alone prevents splashes: 100\% laterally, $92.6 \%$ medially, $77.8 \%$ inferiorly and $0 \%$ superiorly.(37) Lateral contamination has been reported to occur in 5\%.(31) Many HCW erroneously believe that prescription glasses is adequate protection. Many studies have found contamination on the inner surfaces of prescription glasses, with contamination rate higher in longer surgeries (>30 minutes).(6) Conjunctival contamination has been found in $83 \%$ of prescription glasses and no protection, $50 \%$ for surgical loupes, $30 \%$ of facemask with visor, $17 \%$ for hard plastic glasses, and $3 \%$ of disposable plastic glasses during simulation of splashed debris during orthopaedic surgical procedures.(38)

This represents a potential route of infection especially during surgery on the upper aerodigestive tract, where the SARS-nCoV-2 viral load is potentially high.

\subsection{Droplets \& Aerosols}

Viral transmission via eye contamination is very low but it exists. The first reported hepatitis B case via conjunctiva was reported in 1973.(6) In 1982, herpesvirus 1 (B virus) was inoculated directly on the conjunctival mucosa in a chimpanzee resulted in its transmission.(39) In Bischoff WE et al's model, high rates of transocular transmission of live attenuated influenza virus was found in patients, likely via the nasolacrimal duct.(40) Aerosolised virus in surgical plume has been reported to cause iatrogenic infections. Human papillomavirus has been detected in laser plume, and has been reported to cause laryngeal papillomatosis in surgeons.(41) Aerosolised blood generated by high speed rotating instruments and electric coagulator has been found to travel according to the anticipated aerial current generated by the central air conditioning system in the operating room.(42)

Shoham S et al's modelling found that surgical mask with visor, as well as safety eyeglasses with respira- 
tor resulted in eye contamination with oil-based fluorescent dye, whereas the full face shield did not.(43) Loveridge $\mathrm{JM}$ et al demonstrated that the mask visor in the inverted position conferred better protection to the face.(44) Weber RT et al's study of PPE contamination found PPE contamination, including the face shield during simulated AGPs and close contact with patients.(5) The mask under the face shield was contaminated in $4 \%$ of the trials.(5) They also found that generation of infectious aerosol was not limited to AGPs but during routine care.(5) Lindsley WG et al's simulation has found that the use of face shield, and increasing the distance between the coughing source significantly reduced the amount of cough aerosol inhaled ( $\mathrm{p}<0.001$ ). It also reduced the amount of viable virus on the respirator by $70 \%$. (25) The amount of virus deposited on the outer layer of respirator was significantly less $(\mathrm{p}<0.001)$.(25) Use of face shield only caused a modest decrease in the inhalation of airborne particles over the long term.(25) In the first 5 minutes after a cough, the amount of virus on the respirator was $96 \%$ lower when a face shield was worn.(25) After 30 minutes, the amount of virus collected when the face shield was worn was reduced by $81 \%$, likely because smaller particles are able to float around it and accumulate over time.(25) It was also less effective against the small-particle cough aerosol with $68 \%$ reduction of virus deposition as small particles are better able to travel around the face shield and be inhaled.(25)

The use of goggles in addition to gown and mask has resulted in a reduction of nosocomial RSV infection from $43 \%$ to $6 \%$ in admitted children, and $38 \%$ to $5 \%$ in staff.(45)

Inconsistent use of gown, cap and goggles were strongly associated with SARS transmission.(46) Suboptimal adherence to wearing a face shield during aerosol generating procedures (AGP) was significantly ( $<<0.001)$ and independently (OR 3.56, 95\% CI 1.18-10.69) associated with acquiring an influenza-like illness while working on a ward with influenza A and B patients during peak influenza season.(47) This was significant even after adjusting for possible household contacts.

One of the expert taskforce who visited Wuhan developed COVID-19 despite fully gowned with protective suit and the N95 respirator.(12) His first symptom was unilateral conjunctivitis.(12) In addition, van Doremalen N et al's modelling reported viability of SARS-CoV-2 in aerosols.(26) Some authors reported the lack of its presence in air samples obtained from rooms of hospitalised patients with COVID-19 may provide contradictory evidence regarding the extent of aerosol transmission. $(48,49)$ However, another study contradicted this by finding environmental contamination a metre away from a COVID-19 positive 6-month old patient whose only contact is HCW in full PPE.(50)

\subsection{Awareness}

HCW often do not detect contaminations, with reports of $85 \%-100 \%$ of the time.(32, 34, 35, 42, 51, 52) $\mathrm{HCW}$ do not routinely use face shield if they consider the procedures to be unlikely to be associated with potential contamination. $(2,53)$ Traditionally surgeons have not worn eye protection as this is thought to influence vision through the eyepiece of the microscope, discomfort, fogging, reflection and refraction of light, routine lack of availability of eye/face protection, spectacles not fitting under protection, or the feeling that their own spectacles provide adequate protection. $(2,30,37,53,54)$ These may not be a significant problem with face shield.

Chong S et al's study reported that $26.8 \%$ of the surgeons admitted to have splash into their eyes, and only $8.5 \%$ sought testing for disease transmission, suggesting that despite $98.5 \%$ of the study population awareness of conjunctival blood s plash as a route of disease transmission, it is not respected.(37)

\section{CONCLUSION}

Transmission of virus is multi-modal. Conjunctival mucosa presents a real risk for transmission in blood splashes, droplets or aerosols with viable virus, including SARS-CoV-2. HCW often do not detect contaminations to the eye resulting in low compliance of eye protection due to perceived low risk and erroneous belief that prescription glasses is adequate protection. However, modelling and simulation have shown importance of the face shield use in droplet precaution. While it is hard to be tested in isolation as it is part of the package of PPE used in droplet precaution, the limited reports from SARS, COVID-19 and influenza season 
supports its use.

\section{ACKNOWLEDGMENTS}

None

\section{REFERENCES}

1. Roberge RJ. Face shields for infection control: A review. J Occup Environ Hyg. 2016;13(4):235-42.

2. Lakhani R, Loh Y, Zhang TT, Kothari P. A prospective study of blood splatter in ENT. Eur Arch Otorhinolaryngol. 2015;272(7):1809-12.

3. Chao YS, Spry C. CADTH Rapid Response Reports. The Use of N95 Respirators for Protection against Droplet Borne Illness: A Review of the Clinical Effectiveness and Guidelines. Ottawa (ON): Canadian Agency for Drugs and Technologies in Health

Copyright (C) 2017 Canadian Agency for Drugs and Technologies in Health.; 2017.

4. Broussard IM, Kahwaji CI. Universal Precautions. StatPearls. Treasure Island (FL): StatPearls Publishing Copyright (C) 2020, StatPearls Publishing LLC.; 2020.

5. Weber RT, Phan LT, Fritzen-Pedicini C, Jones RM. Environmental and Personal Protective Equipment Contamination during Simulated Healthcare Activities. Ann Work Expo Health. 2019;63(7):784-96.

6. Holzmann RD, Liang M, Nadiminti H, McCarthy J, Gharia M, Jones J, et al. Blood exposure risk during procedural dermatology. J Am Acad Dermatol. 2008;58(5):817-25.

7. Grainger. QuickTips Technical Resources: "Quick Tip \#373. Face shield Protection." 2018 [Available from: https://www.grainger.com/content/qt-face-shield-protection-373.

8. Ji W, Wang W, Zhao X, Zai J, Li X. Cross-species transmission of the newly identified coronavirus 2019-nCoV. Journal of Medical Virology. 2020;92(4):433-40.

9. Zhu N, Zhang D, Wang W, Li X, Yang B, Song J, et al. A Novel Coronavirus from Patients with Pneumonia in China, 2019. New England Journal of Medicine. 2020;382(8):727-33.

10. Li JO, Lam DSC, Chen Y, Ting DSW. Novel Coronavirus disease 2019 (COVID-19): The importance of recognising possible early ocular manifestation and using protective eyewear. Br J Ophthalmol. 2020;104(3):297-8.

11. Wong J, Goh QY, Tan Z, Lie SA, Tay YC, Ng SY, et al. Preparing for a COVID-19 pandemic: a review of operating room outbreak response measures in a large tertiary hospital in Singapore. Can J Anaesth. 2020.

12. Jin YH, Cai L, Cheng ZS, Cheng H, Deng T, Fan YP, et al. A rapid advice guideline for the diagnosis and treatment of 2019 novel coronavirus (2019-nCoV) infected pneumonia (standard version). Mil Med Res. $2020 ; 7(1): 4$.

13. Schwartz J, King CC, Yen MY. Protecting Health Care Workers during the COVID-19 Coronavirus Outbreak -Lessons from Taiwan's SARS response. Clin Infect Dis. 2020.

14. Chan JF, Yuan S, Kok KH, To KK, Chu H, Yang J, et al. A familial cluster of pneumonia associated with the 2019 novel coronavirus indicating person-to-person transmission: a study of a family cluster. Lancet. 2020;395(10223):514-23.

15. Yu P, Zhu J, Zhang Z, Han Y, Huang L. A familial cluster of infection associated with the 2019 novel coronavirus indicating potential person-to-person transmission during the incubation period. J Infect Dis. 2020 . 
16. Huh S. How to train the health personnel for protecting themselves from novel coronavirus (COVID-19) infection during their patient or suspected case care. J Educ Eval Health Prof. 2020;17:10.

17. Rational use of personal protective equipment (PPE) for coronavirus disease (COVID-19). WHO. 19 March 2020.

18. Brewster DJ, Chrimes NC, Do TB, Fraser K, Groombridge CJ, Higgs A, et al. Consensus statement: Safe Airway Society principles of airway management and tracheal intubation specific to the COVID-19 adult patient group. MJA. 16 March 2020.

19. Zhang T, Cui X, Zhao X, Wang J, Zheng J, Zheng G, et al. Detectable SARS-CoV-2 Viral RNA in Feces of Three Children during Recovery Period of COVID-19 Pneumonia. J Med Virol. 2020.

20. Kampf G, Todt D, Pfaender S, Steinmann E. Persistence of coronaviruses on inanimate surfaces and their inactivation with biocidal agents. J Hosp Infect. 2020;104(3):246-51.

21. Yassi A, Moore D, Fitzgerald JM, Bigelow P, Hon CY, Bryce E. Research gaps in protecting healthcare workers from SARS and other respiratory pathogens: an interdisciplinary, multi-stakeholder, evidence-based approach. J Occup Environ Med. 2005;47(1):41-50.

22. Han Q, Lin Q, Jin S, You L. Coronavirus 2019-nCoV: A brief perspective from the front line. J Infect. $2020 ; 80(4): 373-7$.

23. Tellier R. Aerosol transmission of influenza A virus: a review of new studies. J R Soc Interface. 2009;6 Suppl 6(Suppl 6):S783-90.

24. Bahl P, Doolan C, de Silva C, Chughtai AA, Bourouiba L, MacIntyre CR. Airborne or droplet precautions for health workers treating COVID-19? J Infect Dis. 2020.

25. Lindsley WG, Noti JD, Blachere FM, Szalajda JV, Beezhold DH. Efficacy of face shields against cough aerosol droplets from a cough simulator. J Occup Environ Hyg. 2014;11(8):509-18.

26. van Doremalen N, Bushmaker T, Morris DH, Holbrook MG, Gamble A, Williamson BN, et al. Aerosol and Surface Stability of SARS-CoV-2 as Compared with SARS-CoV-1. N Engl J Med. 2020;382(16):1564-7.

27. Gralton J, Tovey E, McLaws ML, Rawlinson WD. The role of particle size in aerosolised pathogen transmission: a review. J Infect. 2011;62(1):1-13.

28. Gamage B, Moore D, Copes R, Yassi A, Bryce E. Protecting health care workers from SARS and other respiratory pathogens: a review of the infection control literature. Am J Infect Control. 2005;33(2):114-21.

29. Davies CG, Khan MN, Ghauri AS, Ranaboldo CJ. Blood and body fluid splashes during surgery-the need for eye protection and masks. Ann R Coll Surg Engl. 2007;89(8):770-2.

30. Endo S, Kanemitsu K, Ishii H, Narita M, Nemoto T, Yaginuma G, et al. Risk of facial splashes in four major surgical specialties in a multicentre study. J Hosp Infect. 2007;67(1):56-61.

31. Bell KM, Clement DA. Eye protection for the surgeon. J R Coll Surg Edinb. 1991;36(3):178-9.

32. Marasco S, Woods S. The risk of eye splash injuries in surgery. Aust N Z J Surg. 1998;68(11):785-7.

33. De Silva R, Mall A, Panieri E, Stupart D, Kahn D. Risk of blood splashes to the eye during surgery. S Afr J Surg. 2009;47(1):7-9.

34. Keogh IJ, Hone SW, Colreavey M, Walsh M. Blood splash and tonsillectomy: an underestimated hazard to the otolaryngologist. J Laryngol Otol. 2001;115(6):455-6.

35. Brearley S, Buist LJ. Blood splashes: an underestimated hazard to surgeons. Bmj. 1989;299(6711):1315.

36. Singh VK, Kalairajah Y. Splash in elective primary knee and hip replacement: are we adequately protected? J Bone Joint Surg Br. 2009;91(8):1074-7. 
37. Chong SJ, Smith C, Bialostocki A, McEwan CN. Do modern spectacles endanger surgeons? The Waikato Eye Protection Study. Ann Surg. 2007;245(3):495-501.

38. Mansour AA, 3rd, Even JL, Phillips S, Halpern JL. Eye protection in orthopaedic surgery. An in vitro study of various forms of eye protection and their effectiveness. J Bone Joint Surg Am. 2009;91(5):1050-4.

39. Perlino C, Hilliard J, Koehler J. Fatal Cercopithecine herpesvirus 1 (B virus) infection following a mucocutaneous exposure and interim recommendations for worker protection. MMWR Morb Mortal Wkly Rep. 1998;47(49):1073-6, 83.

40. Bischoff WE, Reid T, Russell GB, Peters TR. Transocular entry of seasonal influenza-attenuated virus aerosols and the efficacy of n95 respirators, surgical masks, and eye protection in humans. J Infect Dis. 2011;204(2):193-9.

41. Hallmo P, Naess O. Laryngeal papillomatosis with human papillomavirus DNA contracted by a laser surgeon. Eur Arch Otorhinolaryngol. 1991;248(7):425-7.

42. Ishihama K, Sumioka S, Sakurada K, Kogo M. Floating aerial blood mists in the operating room. J Hazard Mater. 2010;181(1-3):1179-81.

43. S. S, C. A-V, M. C, M. H. Comparison of Protection against Ocular Contamination with Disposable Eyewear Products.

44. Loveridge JM, Gozzard C, Bannister GC. The effectiveness of a visor as a surgical barrier: an inverted position is better. J Hosp Infect. 2006;62(2):251-3.

45. Gala CL, Hall CB, Schnabel KC, Pincus PH, Blossom P, Hildreth SW, et al. The use of eye-nose goggles to control nosocomial respiratory syncytial virus infection. Jama. 1986;256(19):2706-8.

46. Lau JT, Fung KS, Wong TW, Kim JH, Wong E, Chung S, et al. SARS transmission among hospital workers in Hong Kong. Emerg Infect Dis. 2004;10(2):280-6.

47. Ng TC, Lee N, Hui SC, Lai R, Ip M. Preventing healthcare workers from acquiring influenza. Infect Control Hosp Epidemiol. 2009;30(3):292-5.

48. Stability and Viability of SARS-CoV-2. New England Journal of Medicine. 2020;382(20):1962-6.

49. Ong SWX, Tan YK, Chia PY, Lee TH, Ng OT, Wong MSY, et al. Air, Surface Environmental, and Personal Protective Equipment Contamination by Severe Acute Respiratory Syndrome Coronavirus 2 (SARSCoV-2) From a Symptomatic Patient. Jama. 2020.

50. Kam KQ, Yung CF, Cui L, Lin Tzer Pin R, Mak TM, Maiwald M, et al. A Well Infant with Coronavirus Disease 2019 (COVID-19) with High Viral Load. Clin Infect Dis. 2020.

51. Kouri DL, Ernest JM. Incidence of perceived and actual face shield contamination during vaginal and cesarean delivery. Am J Obstet Gynecol. 1993;169(2 Pt 1):312-5; discussion 5-6.

52. Kelly G, Gana P, Nielsen T, MacGregor F. The incidence of potential conjunctival contamination in tonsillectomy. J R Coll Surg Edinb. 2000;45(5):288-90.

53. Wines MP, Lamb A, Argyropoulos AN, Caviezel A, Gannicliffe C, Tolley D. Blood splash injury: an underestimated risk in endourology. J Endourol. 2008;22(6):1183-7.

54. Greenland KB, Tsui D, Goodyear P, Irwin MG. Personal protection equipment for biological hazards: does it affect tracheal intubation performance? Resuscitation. 2007;74(1):119-26. 